\title{
OPINIÃO
}

\section{Observações sobre a crise do capitalismo global}

\author{
Igor Zanoni Constant Carneiro Leão ${ }^{55}$
}

RESUMO - O texto discute, a partir de um artigo do Instituto Fernand Braudel, as origens da crise do capitalismo global e o comenta a partir de um ponto de vista keynesiano, recuperando para isto dois artigos clássicos de John Maynard Keynes indicando razões para o otimismo desde que poupança, investimento e mercado de capitais sejam mais intensamente regulados pelo Estado.

Palavras-chave: Crise financeira. Economia internacional. Economia keynesiana.

Este texto procura examinar alguns aspectos da dinâmica da crise econômica que afeta quase todas as economias do mundo na atualidade, bem como as formas possíveis de seu enfrentamento. Escolhemos para isso discutir, dentre os muitos textos que nos chegam sobre o tema, o texto publicado em Braudel Papers, de Norman Gall, Dinheiro, ganância e tecnologia, por ser bastante completo e interessante e dar possibilidade de pensar formas embrionárias de políticas anticíclicas nesse período de capitalismo global.

Começamos por uma breve recapitulação do documento do Instituto Fernand Braudel de Economia Mundial. Em primeiro lugar, ele destaca a ausência de capacidade política e institucional de enfrentar o veloz crescimento dos ativos financeiros como pano de fundo da crise. Como se sabe, a crise foi detonada por uma expansão internacional rápida de crédito habitacional, graças a baixas taxas de juros, que levou a quebras financeiras em vários países, incluindo o socorro prestado pelas autoridades. Essa proliferação de ativos financeiros há alguns anos vinha inflando a demanda industrial e de consumo, elevando os preços especialmente de petróleo, alimentos e água. Essa dinâmica financeira inclui a tomada de empréstimos em mercado com juros baixos, como Japão e Suíça, aplicando-os em países de juros altos, como o Brasil e a Turquia.

Esse aumento da escalada de atividades financeiras, aliado às novas tecnologias de informação, propiciou uma onda de crescimento econômico, criação de novas riquezas e

\footnotetext{
${ }^{55}$ Doutor em Economia pela Universidade Estadual de Campinas. É Professor Associado do Departamento de
} Economia da Universidade Federal do Paraná. Endereço eletrônico: igorzaleao@yahoo.com.br 
novas tecnologias, expansão do comércio, integração da economia mundial e consolidação de valores de justiça social em muitos países. O consumo crescente navegou em crédito fácil como os empréstimos pessoais e os gastos em cartão de crédito para pessoas de baixa renda a juros atraentes. No Brasil observou-se, como parte desse panorama, o grande aumento do crédito consignado que aumentou muito a dívida privada em relação ao PIB. Para o articulista, uma deficiência aí é a política fiscal frouxa praticada pelo governo brasileiro, concedendo inclusive grandes aumentos salariais ao funcionalismo e contratando milhares de novos funcionários, em contradição com sua austera política monetária. Panoramas semelhantes podem ser observados em outros países emergentes, além dos países no centro do capitalismo global.

O boom financeiro alimentou a demanda de risco que foi atendida por hipotecas complicadas, de alto risco, e muitos ativos foram financiados com grande risco de alavancagem e liquidez, expondo muitas das maiores instituições financeiras do mundo ao risco de uma retração global. Esse boom nasceu do afrouxamento na regulamentação das transações financeiras internacionais que nas primeiras décadas após a Segunda Guerra Mundial eram rigidamente regulamentadas pela maioria dos países que se preocupavam mais com a segurança do que com o lucro ou com o crescimento.

O superaquecimento da atividade financeira levou a diversas limitações na infraestrutura observando-se diversos episódios de falta de eletricidade e de congestionamentos em portos, aeroportos e nas ruas da cidade. O maior crescimento levou a uma inflação no preço das commodities, inclusive alimentos e petróleo. A expansão se deu especialmente em países emergentes, mas agora esta expansão está parando. É paradoxal que, diante de inúmeras e urgentes necessidades não satisfeitas de investimento na economia real, tenha sido possível um enorme volume de dinheiro e de crédito na criação de uma enorme bolha financeira.

A crise financeira atual reencena em maior escala a crise asiática de uma década atrás, envolvendo inflação de ativos financeiros em diversos países emergentes como a Tailândia, Malásia e Indonésia até Hong Kong, Coréia do Sul e o desenvolvido Japão, criada por uma interação entre dinheiro, ganância e tecnologia criada e movimentada pela aposta em ativos que foram-se acumulando em busca de rendimentos mais altos. A crise asiática de 1997-98 deu lugar a uma discussão pública sobre a necessidade de reestruturação das finanças internacionais. Falou-se em aumentar a capacidade de ação do FMI, de fortalecer os sistemas financeiros internacionais, de passar das taxas de câmbio fixas para flutuantes para que os 
países pudessem gerir melhor choques econômicos. Algumas dessas metas foram alcançadas, como a melhoria da supervisão dos bancos nos países emergentes, adoção de taxas de câmbio flexíveis, redução da dependência dos empréstimos de curto prazo e superávits em transações correntes. Muitos desses países acumularam grandes reservas de divisas, como o Brasil, cujas reservas superaram sua dívida externa.

Entretanto, as autoridades bancárias relaxaram seus controles, concedendo poderes nos mercados de crédito, a bancos e agências de classificação de risco e multiplicando derivativos cada vez mais distantes da transação original da qual se originaram. Uma inovação financeira significativa foi a criação de um sistema em que os bancos originam hipotecas e então as "securitizam" e distribuem, formando pacotes de hipotecas residenciais, imóveis residenciais até financiamentos de automóveis e outros. Essa securitização feita em grande escala fez com que os ativos se tornassem pouco confiáveis e problemas começaram a surgir no sistema financeiro.

A crise que observamos se originou num pequeno segmento do mercado hipotecário dos Estados Unidos, chegou ao crédito internacional e aos mercados mais amplos através de canais como a exposição aos mercados de hipotecas de alto risco e através de perturbações na atividade bancária e nos mercados financeiros, fragilizando as instituições financeiras mais importantes e a economia real. Em meados de 2007 começou a ser reconhecida a fragilidade dessa armação quando grandes provedores de financiamentos imobiliários residenciais entraram com pedidos de falência, afetando os Estados Unidos, Europa e Japão. A inadimplência sobre dívidas de alto risco se multiplicou com suspensão dos pagamentos de hipotecas pelos devedores, criando o pânico no mercado a partir de 2007.

Essa crise coloca em xeque a tese de que os mercados financeiros tendem ao equilíbrio, bem como a arquitetura da chamada "Nova Economia". Esta se baseava na idéia de que mudanças na estrutura econômica dos Estados Unidos, baseadas na globalização e na informática, tinham levado à aceleração dos ganhos de produtividade, ao crescimento regular permanente, ao baixo índice de desemprego e à imunidade contra os ciclos econômicos. Entretanto, fica claro que a "Nova Economia" não elevou a capacidade institucional de medir os riscos e antecipar os abalos do mercado. Hoje, há uma grande necessidade de segurança, através de ações coletivas entre governos e bancos centrais, criando forças de cooperação mais poderosas que as forças de conflito e de dissolução.

Para o artigo do Braudel Papers, são necessários ajustes que sigam quatro caminhos:

1) Eliminar os juros negativos para refrear o excesso de demanda e parar a inflação; 
2) Eliminar as taxas de câmbio subvalorizadas, reduzindo as distorções no comércio mundial e nos fluxos financeiros e refreando a escalada da inflação mundial;

3) Livrar os mercados financeiros de atividades perigosas e frívolas como a securitização irresponsável e a proliferação de derivativos exóticos;

4) Os governos deveriam lançar programas de modernização de infra-estrutura para consolidar a estabilidade política mostrando preocupação com os setores que enfrentam a diversidade e projetando esperança para o futuro.

Esses pontos ajudariam a evitar maiores turbulências e conflitos futuros e ajudariam a aperfeiçoar a cooperação nos quadros do capitalismo global.

Passando aos nossos comentários, os chamados fundamentos macroeconômicos da economia brasileira eram bons ao abrir-se a crise. As contas públicas estavam equilibradas às custas de um esforço de anos para reduzir a dívida pública financeira por meio de superávits fiscais. É verdade que o dinamismo da economia ligado ao comércio exterior e à expansão do mercado interno fizeram o Estado abrir muitas vagas indispensáveis no setor público e o dinâmico mercado de trabalho levou a correções dos salários nesse setor aviltados desde o governo Collor e a desregulamentação da política salarial. Mas o setor público estava com as contas pelo menos quase em ordem. A política monetária por sua vez enfrentou o problema da inflação das commodities com uma política de juros elevados e metas de inflação balizandoas, o que penalizava as contas públicas mas era uma política ortodoxa e favorável mesmo aos setores rentistas. Essa política auxiliava o câmbio a manter-se sobrevalorizado, mesmo com eventual comprometimento a prazo mais longo das exportações, mas ajudava a manter baixa a inflação.

Aberta a crise, o setor bancário não se encontrou vulnerável por um passado de aguda especulação como seus congêneres norte-americanos e europeus e encontrava-se mesmo em boas condições especialmente por contar com três grandes e sólidos bancos públicos. Ao mesmo tempo, três grandes empresas produtivas estatais ainda remanescentes do ciclo das privatizações nos anos noventa puderam garantir solidez ao tecido econômico. $\mathrm{O}$ governo brasileiro agiu permitindo uma maxidesvalorização, como ocorreu em outros países, devido à necessidade de filiais socorrerem matrizes no exterior, sem permitir uma elevação dos juros, que seria insensata em uma situação de dificuldades financeiras para as empresas. Estas foram socorridas em sua liquidez pela diminuição do compulsório dos bancos e créditos para exportação e investimento pelo BNDES. No conjunto, o governo agiu de forma 
anticíclica com políticas até aqui interessantes, como incentivos à construção civil entre as demais.

Mas a profundidade da crise no futuro está por ser revelada. Um dos trunfos com que hoje contamos é uma indústria com boas vantagens competitivas nos setores ligados ao processamento de produtos naturais, o que foi reforçado pelo boom exportador dos últimos anos. Um dos nossos maiores parceiros comerciais atuais é a China, que ficou incólume à crise financeira por possuir forte regulamentação sobre seu mercado cambial e financeiro, além de ter um consumo potencial muito grande. Caso a China e outros emergentes não baixem muito suas taxas de crescimento, o Brasil poderá enfrentar dificuldades não muito expressivas com os desdobramentos da crise. Além disso, os países desenvolvidos têm tomado medidas que apontam para uma maior intervenção do Estado no saneamento de seus maiores bancos e empresas e mesmo com a política econômica norte-americana ainda por ser delineada pelo futuro governo democrata, espera-se ajuda também para a classe média endividada e uma nova América menos cindida entre o homem comum e os muito ricos. Assiste-se mesmo hoje a um reavivamento dos controles públicos sobre a atividade econômica, nacionalizações e ressurgimento de um keynesianismo que parecia afogado na retórica liberal e das finanças globais.

É possível esperar no futuro uma retomada das taxas expressivas de crescimento na ausência de grandes bolhas especulativas se o caminho for a regulamentação dos fluxos cambiais e financeiros e o maior controle das atividades de bancos em geral. Essa regulamentação terá de ser ainda desenhada, mas caso não seja corre-se o risco de que a história se repita. O ponto a ser enfatizado é que o dinamismo econômico seguro não pode depender de políticas baseadas em pouco Estado e juros elevados. Tampouco em um tecido social pouco solidário e dividido entre classes, etnias, gêneros, idade ou geografia. Para isso são necessárias políticas globais e nacionais concertadas.

Podemos ser otimistas em meio à crise, como Keynes em As Possibilidades Econômicas de nossos Netos (1930) e atingir um objetivo econômico significativo para todos, condicionados por quatro fatores: a capacidade de controlar a população, a determinação em evitar guerras e dissensões civis, disposição para confiar à ciência a preocupação com estas questões e o ritmo de acumulação, que cuidará de si depois de conquistados os três primeiros objetivos.

Em O Fim Do Laissez-Faire (1926), Keynes aponta um critério de agenda do que considerava urgente e desejável fazer no futuro próximo. Em primeiro lugar separar os 
serviços que são tecnicamente sociais dos que são tecnicamente individuais. A mais importante agenda do Estado diz respeito às funções que ninguém adota se o Estado não o faz, isto é, fazer aquelas coisas que atualmente deixam de ser feitas.

Muitos dos maiores males econômicos são frutos do risco, da incerteza e da ignorância. As grandes desigualdades de riqueza, o desemprego dos trabalhadores, a decepção das expectativas razoáveis do empresariado e a redução da eficiência e da produção dependem de indivíduos específicos serem capazes de se aproveitar da incerteza e da ignorância bem como pelo fato dos grandes negócios constituírem frequentemente uma loteria.

A cura desses males, para o autor, deve ser procurada no controle deliberado da moeda e do crédito por uma instituição central e na coleta e ampla publicidade de todos os fatos econômicos que seria útil conhecer. Em segundo lugar é preciso haver um controle social sobre poupança e algum ato coordenado de apreciação sobre a escala da poupança desejável e sobre a organização do mercado de capitais no sentido de fazê-lo distribuir a poupança através dos canais produtivos mais racionais.

Essa agenda delineada nos dois textos citados permitiria uma prosperidade material que poria fim à pobreza e permitiria experiências em um meio seguro sobre a reforma social sintonizando os intelectos e os sentimentos.

Apesar da dificuldade em seguir essa agenda, ela em grande parte está em pauta hoje quando se propõe um papel maior do Estado no controle do sistema financeiro bem como no incentivo à produção e ao consumo. A distribuição de renda e a destinação para políticas sociais da parte do excedente que cabe ao Estado também se colocam para amenizar a crise, bem como controlar o ritmo de crescimento do emprego e da produção.

\section{REFERÊNCIAS}

AGÊNCIA CARTA MAIOR. Disponível em: < http://www.cartamaior.com.br>. Acesso em 4/12/2008.

GALL, N. Dinheiro, ganância, tecnologia. 19 p. Braudel Papers n. 43 - Instituto Fernand Braudel de Economia Mundial, São Paulo, 2008. Disponível em: <http://www.braudel.org.br/publicacoes/bp/bp43_pt.pdf>. Acesso em: 4/12/2008.

INSTITUTO DE ESTUDOS PARA O DESENVOLVIMENTO INDUSTRIAL - IEDI. Disponível em: < http://www.iedi.org.br>. Acesso em 4/12/2008.

KEYNES, J. M. Economia. São Paulo: Ática, 1984. 224 p. (Grandes cientistas sociais, 6). 